\title{
SVN Isouener \\ Personalised care of patients with stroke in China: a challenge and an opportunity
}

\author{
Louis R Caplan, ${ }^{1}$ Marc Fisher ${ }^{2}$
}

To cite: Caplan LR, Fisher M. Personalised care of patients with stroke in China: a challenge and an opportunity. Stroke and Vascular Neurology 2016;1:e000005. doi:10.1136/ svn-2015-000005

Received 30 December 2015 Accepted 2 January 2016

CrossMark

\footnotetext{
${ }^{1}$ Harvard Medical School, Boston, Massachusetts, USA ${ }^{2}$ Beth Israel Deaconess Medical Center, Boston, Massachusetts, USA
}

Correspondence to Professor Louis R Caplan; Icaplan@bidmc.harvard.edu
Interventional treatment of patients with stroke should rekindle a push for 'personalised' medicine. In 1988, more than a quarter of a century ago, one of us (LRC) made a plea for personalised care in an editorial 'What is wrong with Mr. Jones'. 'At that time, the technological tools available to image the brain and its vascular supply were far inferior to those available now. That editorial was focused on patients with transient ischaemic attacks (TIAs). Now experience has accrued concerning detailed personalised clinical and technological evaluation of patients with brain ischaemia and haemorrhage evaluated urgently and even those who have less urgent presentations seen in outpatient settings. Recent focus has centred on rapid management of patients with acute stroke. Randomised trials have now shown the effectiveness of aggressive interventional endovascular treatment of patients with ischaemic stroke diagnosed using modern brain and vascular imaging technology. ${ }^{2-7}$

Much has been written about these recent randomised trials of interventional treatment of selected individuals who have acute brain ischaemia. These studies proved that patients carefully selected using advanced brain and vascular imaging had better outcomes by applying interventional techniques that opened occluded brain-supplying arteries than controls primarily treated only with standard intravenous thrombolysis. ${ }^{2-7}$ The discussions and editorials ${ }^{8} 9$ that followed publication and presentations of the results of these trials have understandably mostly consisted of analyses that answer very practical questions. What is the time frame in which the treatment is likely to succeed? How is success measured? Which patients with what vascular lesions and what volume of brain infarction should be treated? Does the amount of collateral circulation already mobilised matter and, if so, how should it be measured? Does the 'clot burden' shown before treatment affect the ability to open the artery or bleeding after clot removal? What technology should be used to open the blocked arteries-intra-arterial thrombolytics, stent retrievers, suction or combinations of these? What should be the qualifications and training of those who perform the interventional clot retrieval therapy?

Other discussions focused on general community resource issues. Can patients with acute stroke be treated in the ambulance or primary stroke centre close to where the stroke developed? If so, is it economically and practically feasible to send a 'stroke mobile' equipped with a CT scanner and blood analysis equipment ${ }^{8-10}$ Where should governmental regulations mandate sending the patient? To the nearest primary stroke centre or to specialised advanced stroke centres equipped with the personnel and technology to provide rapid intra-arterial interventions?

However, in this Editorial, we will not focus on any of these practical issues. We intend to wax philosophical on and attempt to place these latest stroke trials into the broad history of stroke and to argue how these trials could and should influence the future of stroke diagnosis and management. We also aim to place this history in the context of stroke care in Asia and in China in particular. The modern history of stroke is short and much has evolved during our careers as trainees and stroke physicians. We emphasise our own experiences because that is what we know best and know first-hand.

During the first half of the 20th century, therapeutic nihilism reigned supreme. There were no doctors who specialised in stroke, few neurologists, and no way to effectively visualise the brain and its vasculature during life. There were few treatments and none were well studied.

Knowledge about stroke advanced during the 1920's in France by Charles Foix and his colleagues $^{11}$ and in Boston during the 1950 1975 period by Miller Fisher and his colleagues Raymond Adams and Pierson Richardson. ${ }^{12}$ The technique was an old one that had been pursued in understanding other brain diseases by Charcot and 
colleagues-clinical-pathological analyses. A careful study of brains at necropsy of patients with ischaemic stroke showed the usual sites and causes of vascular occlusions, the nature of various vascular and cardiac lesions, and the usual accompanying clinical signs. Brain and subarachnoid haemorrhages were also analysed in detail. Virchow had emphasised the triad (endothelium, blood, and blood flow and blood clotting) that must be understood to uncover the pathophysiology of how the vascular lesions became clinically active. Laboratory analyses of the blood and the physiology of blood flow added to that understanding. LRC was taught and learned during a stroke fellowship with Dr Fisher in 1969 that clinically and pathologically, no two strokes and no two stroke patients were exactly the same when studied in depth.

In the latter part of the 20th century, epidemiological studies and stroke registries added considerable quantitative information. How frequent were various mechanisms of brain ischaemia and haemorrhage? What were the age distributions of various stroke mechanisms and vascular lesions? Were there differences according to sex, race, geographical location, and financial and social status? What were the risk factors that promoted strokes? How could these risk factors be best controlled to prevent stroke from happening? Nearly all of these studies included only Caucasian patients living in the USA and Europe.

With the advent of CT scanning in the 1970s and MR scans in the 1980s and beyond, it became possible to image the brain and its blood supply quickly and safely. With diffusion-weighted/perfusion-weighted MRI (DWI/ PWI), CT and MR angiography, and CT perfusion (CTP) imaging, the vascular occlusive lesions and the ischaemic core and the ischaemic penumbra (potentially salvageable ischaemic tissue and the target of acute stroke therapy) could be identified and their extent approximated. Echocardiography and coronary angiography gave considerable information about the heart and its function and its vascular lesions. Blood contents and coagulation factors could be analysed quickly and accurately.

Clinicians could now perform clinical-imaging analyses of what was wrong, that is, ischaemic lesion location and extent, with their patients with stroke during life even during the first hours after stroke onset, much as physicians during preceding decades had done only at necropsy. More stroke doctors were trained. Units devoted solely to the care of patients with stroke became very popular in Europe and spread to the USA. ${ }^{13}$ However, what was missing was detailed information about treatment.

Beginning in the $1970 \mathrm{~s}$, randomised therapeutic stroke trials were planned and carried out. Initially, therapeutic trials were mostly performed in the USA and Europe but towards the end of the century and during the first quarter of the 21st century there were many Asian trials; in many multicentre trials, Asian patients predominated. Trials sought to enroll large numbers of patients to attain statistically significant results. In order to acquire numbers, the trials that studied stroke prevention had to lump all patients with brain ischaemia (eg, TIAs and minor strokes) together. The results obtained were general and not readily applied to individual patients with varied risk factors and specific stroke mechanisms and findings. The absence of modern brain and vascular imaging available during these early trials limited the application of these results to individual patients. However, even during the 1990s and the first decade of the present century, intravenous thrombolytic trials recruited and studied lumped patients with acute strokes characterised mostly by time since stroke onset. In the landmark NINDS trial of alteplase, ${ }^{14}$ clinical stroke subtyping was obtained but in the ECASS-3 study ${ }^{15}$ that showed that alteplase was effective in the 3-4.5 $\mathrm{h}$ time window this basic information was not obtained, making it impossible to know if all ischaemic stroke subtypes actually benefit when treated during this later time window. In these early thrombolytic trials, only a plain head CT scan was performed, primarily to exclude intracranial haemorrhage, so that there was no demonstration of a vascular occlusion and the effect of alteplase on opening previously occluded arteries, so that the target of thrombolysis could not be evaluated. The results of these trials are difficult to apply to patients in whom detailed brain and vascular imaging defines the vascular lesions, the regions of brain infarction and brain ischaemia and the extent of the ischaemic core and penumbra.

In contrast to the data required in these older thrombolytic and stroke prevention trials, the recent interventional trials required advanced brain and vascular imaging and blood testing. ${ }^{2-7}$ This information guided prognosis and choice of acute treatment. Knowing the nature of the stroke mechanisms and acute findings, along with cardiac and other blood marker studies, helped select patients most likely to benefit from acute revascularisation. This approach can be categorised as the personalised approach to the care of patients with stroke. In editorials in general medical journals, the term personalised has been used mostly to apply to genetic data. However, genetics is just one component of the information that can be gleaned from and applied to individuals.

Stroke is a very serious and very expensive condition. It is the major cause of long-term morbidity. Rehabilitation is expensive as are years of loss of the ability to work and to support themselves and their families. Individuals with stroke symptoms should now be studied in depth using blood, cardiac, and brain and vascular imaging examinations. These can be performed quickly and safely. These data can be used to tailor acute treatment and stroke and myocardial infarction prevention strategies for that individual patient. Perhaps in the future, genetic data can be shown to be of added value.

Patients with an acute neurological deficit suggestive of a stroke should be taken directly, whenever possible, 
to primary or advanced stroke centres that have the trained personnel and technology to optimally care for them. Since many smaller centres receiving patients with stroke may not have physicians trained in vascular neurology, the availability of such experts via telemedicine provides a solution to potential expertise gaps. Patients with subacute symptoms can be taken to centres that can rapidly evaluate patients with TIAs and strokes. These centres, manned by experienced and trained stroke physicians, have been shown to be every effective for preventing subsequent strokes in the UK and Europe and should be encouraged in the USA and in Asian countries. ${ }^{16-18}$ These centres can evaluate patients thoroughly and quickly as outpatients without incurring the additional expense of hospitalisation. They have access to modern technology and can select the evaluation appropriate for each individual patient.

Future randomised therapeutic trials should target specific stroke issues in patients who have had a thorough evaluation. In patients with rare or infrequent conditions, databases and registries of treatment and responses can be useful in helping physicians to choose treatment for these conditions. The old strategy of lumping diverse groups has had its utility in times past but will be of limited use in the future. The availability of advanced CT and MRI studies as well as newer cardiac testing such as implantable monitors now allows for a more precise understanding of the cause of an ischaemic stroke and whether an individual patient can benefit from acute stroke therapy. These data are also very important in choosing the most effective preventive treatment of that particular patient. If we are truly to espouse real 'personalised medicine' we need to move ahead. The guide should be the golden rule. How would you like yourself or your spouse or your parent to be managed. By non-experts using recipes from trials based on large groups of inadequately evaluated individuals or by highly trained physicians using data from trials and databases and registries that contain very specific and detailed information?

In China and in the rest of Asia, there are additional challenges to delivering personalised medicine but there are also advantages. Serving the very large number of patients (>one billion) in China and their geographic dispersion with many rural areas that are inadequately supplied with trained physicians provides the greatest challenge. There is now a lack of well-trained, experienced neurologists and stroke physicians to care for the Chinese population. The short times physicians are given to see individual patients also hampers doctors' ability to deliver true personalised care.

There are also important opportunities to study stroke and cerebrovascular disease in China. Results of these studies can facilitate the delivery of personalised stroke medicine. The large numbers of patients allow the study of prespecified subgroups that will be large enough to ensure statistical validity. Chinese stroke physicians and researchers have developed excellent corroborative arrangements and organisations to plan research and data accrual. They have already created computerised registries to acquire large bodies of information. In China, it should be possible for the government and organisations of stroke physicians to direct the creation of stroke centres. Planning for effective delivery of patients to primary and advanced stroke centres can then begin and rules can be derived for optimum delivery of patients to these stroke centres. Personalised care can become a reality in China, Asia, as well as in the USA and Europe. However, it will take time and effective planning.

Competing interests None declared.

Provenance and peer review Not commissioned; internally peer reviewed.

Open Access This is an Open Access article distributed in accordance with the Creative Commons Attribution Non Commercial (CC BY-NC 4.0) license, which permits others to distribute, remix, adapt, build upon this work noncommercially, and license their derivative works on different terms, provided the original work is properly cited and the use is non-commercial. See: http:// creativecommons.org/licenses/by-nc/4.0/

\section{REFERENCES}

1. Caplan LR. TIAs: we need to return to the question 'What is wrong with Mr. Jones?' Neurology 1988;38:791-3.

2. Berkheimer OA, Fransen PSS, Beumer D, et al, for the Mr. CLEAN Investigators. A randomized trial of intraarterial treatment for acute ischemic stroke. N Engl J Med 2015;372:11-20.

3. Goyal M, Demchuk AM, Menon BK, et al, for the ESCAPE Trial Investigators. Randomized assessment of rapid endovascular treatment of ischemic stroke. N Engl J Med 2015;372:1019-30.

4. Saver J, Goyal M, Bonafe A, et al, for the SWIFT PRIME Investigators. Solitaire TM FR With the Intention For Thrombectomy as PRIMary Endovascular treatment for acute ischemic stroke. N Engl J Med 2015; 372:2285-95.

5. Campbell BCV, Mitchell TJ, Kleinig HM, et al, for the Extend-IA Investigator. Endovascular therapy for ischemic stroke with perfusion-imaging selection. N Engl J med 2015;372:1009-18.

6. Jovin TG, Chamorro A, Cobo E, et al, REVASCAT Investigators. Thrombectomy within 8 hours after symptom onset in ischemic stroke. N Engl J Med 2105;372:2296-306.

7. Badhiwala JH, Nassiri F, Alhazzani W, et al. Endovascular thrombectomy for acute ischemic stroke: a meta-analysis. JAMA 2015;314:17.

8. Hacke W. Interventional thrombectomy for major stroke-a step in the right direction. N Engl J Med 2015;372:76-7.

9. Caplan LR, Furlan AJ, Hacke W. Acute ischemic stroke therapy: the way forward. JAMA Neurol 2015;72:1405-6.

10. Rajan S, Baraniuk S, Parker S, et al. Implementing a Mobile Stroke Unit Program in the United States: why, how, and how much? JAMA Neurol 2015;72:229-34.

11. Caplan LR. Charles Foix - the first modern stroke neurologist. Stroke 1990;21:348-56.

12. Caplan LR, Mohr JP, Ackerman RA. In Memorium: Charles Miller Fisher (1913-2012). Arch neurol 2012;69:1208-9.

13. Stroke Unit Trialists' Collaboration. Collaborative systematic review of the randomized trials of organized in-patient (stroke unit) care after stroke. BMJ 1997;314:1151-9.

14. The National Institute of Neurological Disorders and Stroke rt-PA Study Group. Tissue plasminogen activator for acute ischemic stroke. N Engl J Med 1995;333:1581-7.

15. Hacke W, Kaste M, Bluhmk E, et al, for the ECASS Investigators. Thrombolysis with alteplase 3 to 4.5 hours after acute ischemic stroke. N Engl J Med 2008;359:1317-29.

16. Lavallée $\mathrm{PC}$, Meseguer $\mathrm{E}, \mathrm{Abboud} \mathrm{H}$, et al. A transient ischaemic attack clinic with round-the-clock access (SOS-TIA): feasibility and effects. Lancet Neurol 2007;6:953-60.

17. Rothwell PM, Giles MF, Chandratheva A, et al. Effect of urgent treatment of transient ischaemic attack and minor stroke on early recurrent stroke (EXPRESS study): a prospective population-based sequential comparison. Lancet 2007;370:1432-42.

18. Amarenco P, Lavallée PC, Labreuche $\mathrm{J}$, et al, on behalf of the TIAregistry.org Investigators. One year risk of stroke after transient ischemic attack or minor ischemic stroke. N Engl J Med 2016. In press. 